\title{
Corrosion Inhibition of Galvanized Steel by Cobalt(II) Nitrate
}

\author{
Thu Thuy Thai, ${ }^{a, \dagger}$ Anh Truc Trinh, ${ }^{\mathrm{a}, \mathrm{b}}$ Thi Thanh Tam Pham, ${ }^{\mathrm{c}} \quad$ Xuan Hoan Nguyen, ${ }^{\mathrm{c}}$ Gia Vu Pham, \\ Thi Xuan Hang To a, b \\ anstitute for Tropical Technology, Vietnam Academy of Science and Technology, A13 Building, 18 Hoang Quoc Viet, Cau Giay, Hanoi, \\ Vietnam \\ ${ }^{\mathrm{b}}$ Graduate University of Science and Technology, Vietnam Academy of Science and Technoloy, 18 Hoang Quoc Viet, Cau Giay, Hanoi, \\ Vietnam \\ ${ }^{\mathrm{c}}$ Faculty of Chemistry, VNU University of Science, Vietnam National University, 19 Le Thanh Tong, Hanoi, Vietnam \\ †Corresponding author: ttthuy@itt.vast.vn
}

Received: 15 December, 2020; Accepted: 8 May, 2021; Published: 20 May, 2021

This study presents the inhibitive property of Co(II) ions in the corrosion protection of commercial hot-dip galvanized steel in aggressive solution. The polarization measurements reveal the action of $\mathrm{Co}$ (II) cations in the anodic branch with the inhibitive efficiency determined at $96 \%$ for $0.01 \mathrm{M}$ of $\mathrm{Co}(\mathrm{II})$. The corrosion resistance was reinforced by a passive layer formed at $\mathrm{Zn}$ surface, that was assessed by the electrochemical measurements. The existence and the crystal structure of this protective layer was analyzed by field-emission scanning electron microscopy observations. X-ray diffraction analysis was confirmed the formation of zinc cobalt hydroxide and cobalt zinc oxide on the $\mathrm{Zn}$ surface that attributed to the inhibitive action of the Co cations.

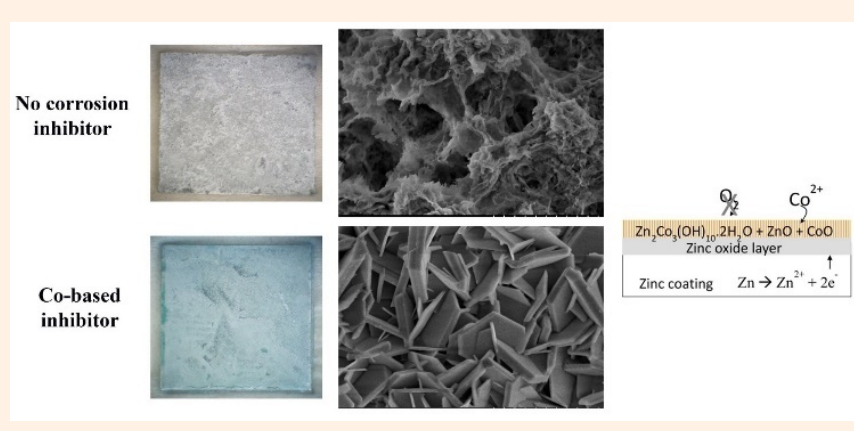

Keywords Galvanized steel; Cobalt; EIS; Polarization; Inhibitor

\section{INTRODUCTION}

Steel is the most used and recycled material in industrial construction with varieties of applications. Unfortunately, like the other metals, steel is sensible to be corroded in environmental working conditions, leading to the reduction of its mechanical properties. Among various anti-corrosion processes to prolong the lifetime of steel, zinc coating plays an important role as zinc metal owns itself a high resistance and a reasonable price $[1,2]$. Zinc coating can help to improve the barrier properties but also acts as a "sacrifice anode" in order to protect steel/iron substrate [3]. Steel items are submerged in molten hot zinc or well known as galvanized steel - that is the most common process to apply a thick layer of zinc coating on the surface.

In light of the role of zinc coating, the corrosion mechanism of zinc has been studied in aggressive medium $[1,4,5]$ It is accepted that the inhibitive layer composed mainly of zinc oxide/zinc hydroxide leads a passivation of the zinc surface $[1,6]$. If an organic inhibitor is used, this layer is also composed with a part of the complex $\mathrm{Zn}^{2+}$ chelate that covers the $\mathrm{Zn}$ surface and suppresses the corrosion procedure [7, 8]. Compounds of hexavalent chromium $\mathrm{Cr}(\mathrm{VI})$ have been added in a zinc bath during the production process as effective corrosion inhibitors. Among the effective alternatives to the use of $\mathrm{Cr}(\mathrm{VI})$ as inhibitors, rare earth salts, especially cerium salts, are being interested to prevent the corrosion of zinc in alkaline solutions [9-11]. The protective film is made of cerium hydroxide $\mathrm{Ce}(\mathrm{OH})_{3} / \mathrm{Ce}(\mathrm{OH})_{4}$ and cerium oxide $\mathrm{Ce}_{2} \mathrm{O}_{3}, \mathrm{CeO}_{2}$ can be found in the intermediate and inner layers of the protective film, while the outer layer is composed of zinc hydroxide [9].

In recent years, the use of cations of transition metals like $\mathrm{Zn}, \mathrm{Mn}, \mathrm{Ni}, \mathrm{Co}$, etc. as corrosion inhibitors for various types of steel like carbon steel [12] and mild steel [13] has been reported. Cobalt cation is a promising inhibitor also for galvanized steel [3]. The inhibitive ability of cobalt is based on its multi-oxidation state $\left(\mathrm{Co}^{2+}, \mathrm{Co}^{3+}\right.$, and $\left.\mathrm{Co}^{4+}\right)$ and its oxidation-reduction potential $\left(E_{\mathrm{Co}(\mathrm{III}) / \mathrm{Co}(\mathrm{II})}=+1.92 \mathrm{~V}\right)$ close to that of chromate $\left(E_{\mathrm{Cr}(\mathrm{VI}) / \mathrm{Cr}(\mathrm{III})}=+1.36 \mathrm{~V}\right)[14,15]$. 
In alkaline solutions, cobalt ions react as a cathodic inhibitor by reducing the cathodic reaction rate with the precipitation of cobalt hydroxide at active sites. Leidheiser et al. reported that a slight protective effect can be obtained by submerging of the zinc crystal substrates at $0.05 \mathrm{M}$ and 0.1 $\mathrm{M}$ of a cobalt(II) chloride solution and then by heating at $80^{\circ} \mathrm{C}$ in air for $2 \mathrm{~h}$ [3]. This phenomenon was proved by cathodic polarization curves. However, nitrate ions act as an anodic inhibitor in the corrosion protection of 2024-T3 aluminum alloy in a $3.5 \% \mathrm{NaCl}$ solution [16]. In a $10 \mathrm{wt} \%$ sulfuric acid solution, addition of cobalt passivated the low alloy steel by forming the thick and uniform rust layer which was mainly cobalt ferrite [17].

In the present work, the inhibition properties of cobalt ions have been investigated under a low concentration in the corrosion protection of a commercial hot-dip galvanized (HDG) steel on which a heterogeneous zinc coating is formed. This work helps to deepen our understanding of the inhibitive mechanism by cobalt ions that lead to be applied in the commercial pretreatment process of galvanized steel.

\section{METHODS AND EXPERIMENTAL}

\section{A. Materials}

HDG steel substrates ( $\mathrm{Zn}$ coating of $35-40 \mu \mathrm{m}$ thick) were ultrasonicated in acetone for $10 \mathrm{~min}$, degreased in Turco NC $4215 \mathrm{LT}$ alkaline solution $\left(10 \mathrm{~min}, 50^{\circ} \mathrm{C}\right)$, and rinsed in ethanol for cleaning. Before the inhibition experiment, the HDG steel samples were embedded in epoxy resin to protect the sample edges and to assure the surface working area of $4 \mathrm{~cm}^{2}$ exposed to the electrolyte.

Cobalt(II) solutions were prepared from cobalt(II) nitrate hexahydrate (99\%, Sigma-Aldrich). The concentration was varied from 0.001 to $0.01 \mathrm{M}$ in the presence of $0.1 \mathrm{M} \mathrm{NaCl}$ as an electrolyte environment.

\section{B. Experimental techniques}

X-ray diffraction (XRD) measurements were made using Bruker D8-Advance with a $\mathrm{Cu} \mathrm{K} \alpha$ radiation $(\lambda=0.154 \mathrm{~nm})$. Morphology of the HDG steel samples were observed using

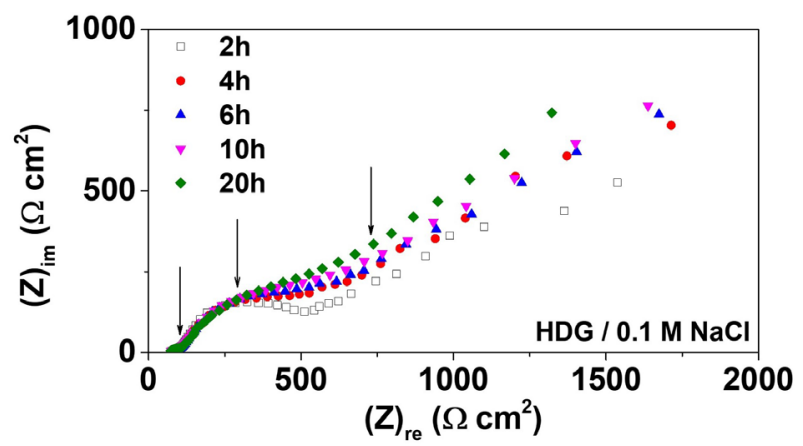

Figure 1: Nyquist plot obtained for the pre-cleaned HDG steel sheet in $0.1 \mathrm{M} \mathrm{NaCl}$ during the immersion time. field-emission scanning electron microscopy (FE-SEM) (Hitachi S-4800).

Inhibition properties of cobalt(II) ions were investigated by electrochemical measurements on Bio Logic SP-300 with the help of $0.1 \mathrm{M} \mathrm{NaCl}$ as an electrolyte solution. A classical three-electrodes system was used; a pre-cleaned HDG steel sample as a working electrode, a $\mathrm{Pt}$ rod as a counter electrode, and an $\mathrm{Ag} / \mathrm{AgCl} / \mathrm{KCl}$ saturated electrode as a reference electrode (RE). Electrochemical impedance spectroscopy (EIS) measurements were done at open-circuit potential (OCP), $10 \mathrm{mV}$ of amplitude, and the frequency from 100 $\mathrm{kHz}$ to $10 \mathrm{mHz}$. The polarization curves were analyzed at a scan rate of $10 \mathrm{mV} \mathrm{min}{ }^{-1}$ in the range between -300 and $+300 \mathrm{mV}$ with respect to the OCP. Different HDG steel samples were used depending on the anodic or cathodic branch characterization. All the tests were performed in triplicate to assure the reproducibility.

\section{RESULTS AND DISCUSSION}

\section{A. Influence of concentration of $\mathrm{Co}(\mathrm{II})$ ions in the corrosion protection of HDG steel}

The electrochemical behavior of the HDG steel samples was firstly characterized by the EIS measurements. Figure 1 represents a Nyquist plot obtained for the pre-cleaned HDG steel samples during immersion times from 2 to $20 \mathrm{~h}$. One capacitive semi-circles at a high frequency part and a linear line at a low frequency part are observed in the Nyquist plot. The first semi-circle is attributed to charge transfer, and the linear tail indicates a diffusion process associated with the oxygen reduction/zinc dissolution [18]. Some points appear at very high frequencies and are linked to a film effect related to adsorption of corrosion products on the metallic surface. The shape of Nyquist curves and the impedance values have not significantly modified during $20 \mathrm{~h}$ of the test. This is due to continuous dissolution of zinc in the corrosive medium.

The electrochemical properties of the HDG steel electrode are modified when adding $\mathrm{Co}$ (II) ions in the electrolyte solution. Figure 2 shows Nyquist plots of the HDG steel samples immersed at different times in $0.1 \mathrm{M} \mathrm{NaCl}$ in the pres-

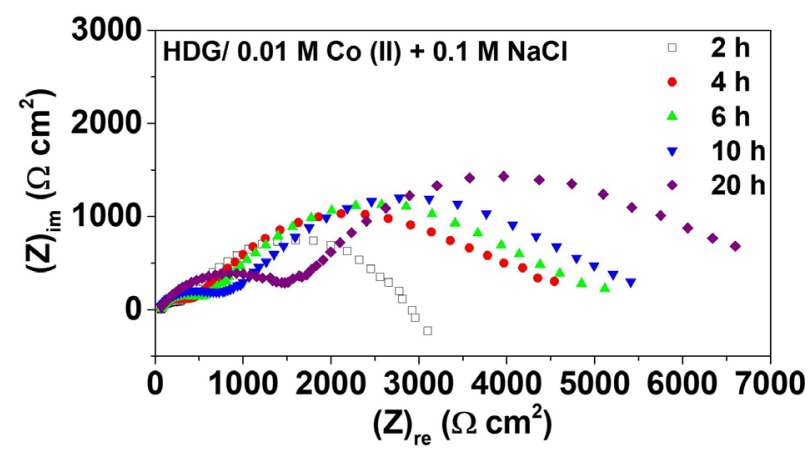

Figure 2: Nyquist plot obtained for the pre-cleaned HDG steel sheet immersed in $0.1 \mathrm{M} \mathrm{NaCl}$ containing $0.01 \mathrm{M} \mathrm{Co}(\mathrm{II})$ during immersion times. 

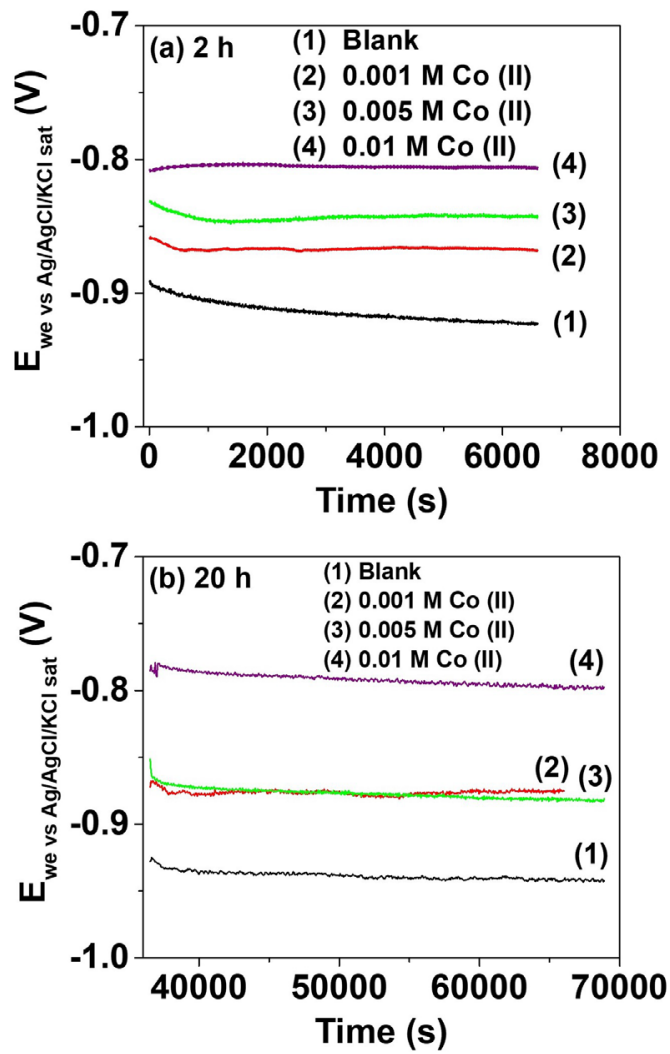

Figure 3: OCP evolution obtained for the pre-cleaned HDG steel sheet immersed in $0.1 \mathrm{M} \mathrm{NaCl}$ containing different concentrations of Co(II) after (a) $2 \mathrm{~h}$ and (b) $20 \mathrm{~h}$.

ence of $0.01 \mathrm{M} \mathrm{Co}(\mathrm{II})$. Two semi-circles can be observed and the impedance values are higher than that immersed in the reference solution. While increasing the immersion time, the diameter of the semi-circle is developed. This demonstrates that the presence of the Co(II) ions in the electrolyte solution affects the electrochemical impedance behavior of the HDG steel sample.

To understand the role of the $\mathrm{Co}(\mathrm{II})$ ions, $0.1-\mathrm{M} \mathrm{NaCl}$ solutions containing different concentrations of the $\mathrm{Co}$ (II) ions from 0.001 to $0.01 \mathrm{M}$ were prepared. Figure 3 shows the evolution of the OCP value obtained after 2 and $20 \mathrm{~h}$ immersion of the HDG steel in the experimental solutions. There is a difference of the OCP value in the absence and in the presence of the $\mathrm{Co}^{2+}$ ions. When the HDG steel sample is immersed in a blank solution $\left(0.1 \mathrm{M} \mathrm{NaCl}\right.$ without $\left.\mathrm{Co}^{2+}\right)$, the $\mathrm{OCP}$ value is about $-0.89 \mathrm{~V} / E_{\mathrm{RE}}$ and is slowly decreased to $-0.92 \mathrm{~V} / E_{\mathrm{RE}}$ after $2 \mathrm{~h}$ [Figure 3(a)]. In the presence of the $\mathrm{Co}^{2+}$ ions, the more the $\mathrm{Co}(\mathrm{II})$ ions in the solution are, the more the OCP value of system tends to be positive: $-0.86 \mathrm{~V}$ $\left(0.001 \mathrm{M} \mathrm{Co}^{2+}\right),-0.84 \mathrm{~V}\left(0.005 \mathrm{M} \mathrm{Co}^{2+}\right)$, and $-0.8 \mathrm{~V}(0.01$ $\mathrm{M} \mathrm{Co}^{2+}$ ) with respect to the potential of the reference electrode. This can be supposed that $\mathrm{Co}^{2+}$ ions show their reactivity at the anodic branch. After $20 \mathrm{~h}$ of immersion, in the case of the HDG steel immersed in the solutions containing 0.001 and $0.01 \mathrm{M} \mathrm{Co}(\mathrm{II})$, the recorded OCP parameter is stable at the similar values when compared to these ones obtained after $2 \mathrm{~h}$ of immersion [Figure 3(b)]. For the HDG
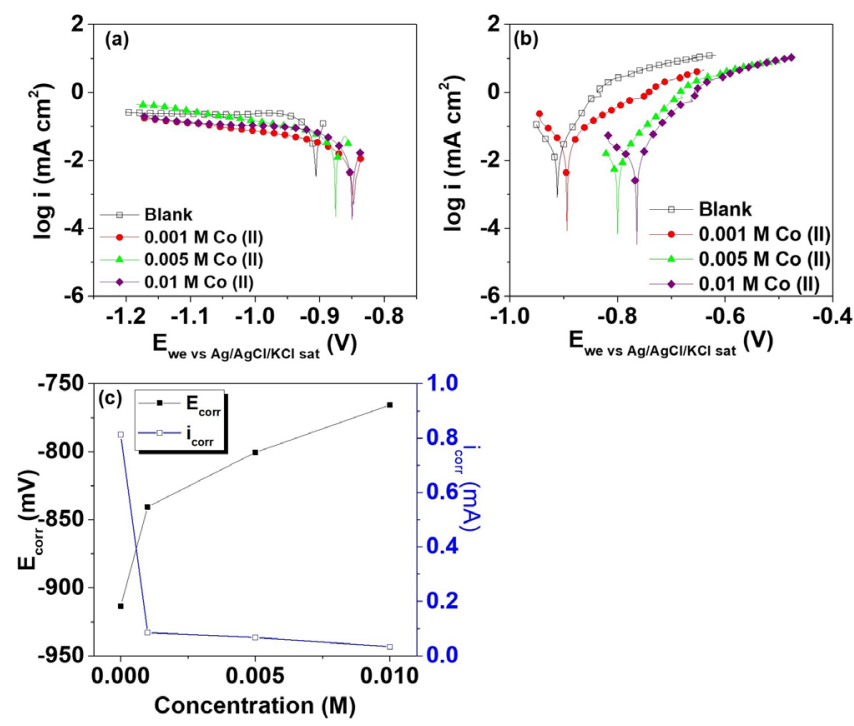

Figure 4: Cathodic (a) and anodic (b) polarization curves obtained for HDG steel after $20 \mathrm{~h}$ immersed in the electrolyte solutions with and without the Co ions. Evolution of the corrosion potential $E_{\text {corr, }}$ the corrosion current densities $I_{\text {corr }}$ as a function of the Co concentration (c).

steel sample immersed in the solution containing $0.005 \mathrm{M}$ $\mathrm{Co}(\mathrm{II})$, this parameter is slightly decreased to $-0.87 \mathrm{~V}$. However, the OCP values of all studied systems always take place in the anodic direction compared to the one obtained for the HDG steel immersed in the blank solution. This suggests that the inhibitive properties of Co(II) are still effective after $20 \mathrm{~h}$ of immersion but effectiveness depends on the concentration of the Co cations.

Potentiodynamic polarization was also used to investigate the inhibitive behavior of the $\mathrm{Co}(\mathrm{II})$ ions for the HDG steel substrate. Figure 4 shows the anodic and cathodic polarization curves of the HDG steel substrate after $20 \mathrm{~h}$ of exposure in $0.1 \mathrm{M} \mathrm{NaCl}$ in the presence of the $\mathrm{Co}$ (II) ions with different concentrations. The evolution of the corrosion potential $E_{\text {corr }}$ and the corrosion current densities $I_{\text {corr }}$ were also reported. A curve recorded for the HDG steel substrate immersed in the reference solution $(0.1 \mathrm{M} \mathrm{NaCl}$, a blank solution) is also presented. Figure 4(a) shows that, in the cathodic range, the cathodic current densities obtained for the polarization curves with the inhibitor are similar to the one of the blank solution. None of the cathodic protection effect is observed.

It is clear from Figure 4(b) that the anodic current densities are decreased following the order: blank $>0.001 \mathrm{M}>$ $0.005 \mathrm{M} \approx 0.01 \mathrm{M} \operatorname{Co}(\mathrm{II})$. This means that the higher concentration of the inhibitor could promote the inhibitive protection. From 0.001 to $0.01 \mathrm{M}$ of $\mathrm{Co}(\mathrm{II}), E_{\text {corr }}$ trends to shift to a more positive direction [Figure 4(c)]. These results suggest that the cobalt salt can be considered as an anodic inhibitor. In addition, after the cathodic polarization, the substrate gets the visibly blackened trace which disappeared in a diluted nitric acid solution, suggesting the formation of 
Table 1: Inhibitive efficiency ( $\left.I_{\text {eff }}\right)$ obtained after $20 \mathrm{~h}$ of immersion of HDG steel in the electrolyte solutions containing Co(II).

\begin{tabular}{cc}
\hline Co(II) concentration $(\mathrm{M})$ & $I_{\text {eff }}(\%)$ \\
\hline Blank & 0 \\
0.001 & 90 \\
0.005 & 92 \\
0.01 & 96 \\
\hline
\end{tabular}

metallic cobalt. In this case, the corrosion occurs at the surface, leading to the corrosion process by dissolution of zinc $\left(\mathrm{Zn} \rightarrow \mathrm{Zn}^{2+}-2 \mathrm{e}^{-}\right)$. In the presence of the cobalt ions at polarized conditions, metallic cobalt can be formed at the surface via the reaction $\mathrm{Co}^{2+}+2 \mathrm{e}^{-} \rightarrow$ Co. This phenomenon was also observed for a polarized zinc single-crystal sample at $-1.15 \mathrm{~V}$ with 0.5 and $1 \mathrm{M} \mathrm{CoCl}_{2}$, revealing the activity of cobalt at the high cathodic current [3].

Based on the anodic polarization curves in Figure 4(b), the quantitative measurements were made to extract the parameters. The current densities are determined from the anodic polarization curves through the Tafel extrapolation and are used to calculate the inhibitive efficiency $\left(I_{\text {eff }}\right)$ by a following equation [18];

$$
I_{\text {eff }}=\frac{i_{\text {corr }}^{0}-i_{\text {corr }}}{i_{\text {corr }}^{0}} \times 100(\%),
$$

where $i_{\text {corr }}$ and $i_{\text {corr }}^{0}$ are current densities in the presence and in the absence of the inhibitor, respectively. Table 1 represents the $I_{\text {eff }}$ values for different Co concentrations. It shows that the inhibitive efficiency of more than $90 \%$ is obtained for 0.005 and $0.01 \mathrm{M}$ of $\mathrm{Co}(\mathrm{II})$. This proves the inhibitive ability of the Co(II) salt to HDG steel, and this protective ability tends to happen as an anodic inhibitor.

The EIS measurements are used to investigate the electrochemical behavior of the HDG steel substrate. Figure 5 presents the Nyquist plots obtained when the steel substrate is immersed in the $0.1 \mathrm{M}$ solution containing the $\mathrm{Co}$ (II) ions after 2 and $20 \mathrm{~h}$. Two capacitive loops have been always observed; the first appeared at the high frequency is related to the protective inhibition phenomenon [18], while the second located at the low frequency can be attributed to the double layer of charge transfer when the Co ions absorbs on the surface $[3,20]$. After $2 \mathrm{~h}$ of immersion, the modulus value at the low frequency for the solution with $\mathrm{Co}^{2+}$ is greater than 10 times when compared to the value obtained for the blank solution. The diameter and the shape of second semi-loop are also changed depending on the concentration of the inhibitor. The diameter of the second one formed at $0.001 \mathrm{M}$ of $\mathrm{Co}(\mathrm{II})$ is not important compared to the result obtained at 0.005 and $0.01 \mathrm{M}$. This may be due to the inhibitive reactivity of the higher concentration of the Co ions.

The Nyquist plots in Figure 5(b) prove the effectivity of the $\mathrm{Co}$ (II) ions in a long immersion time. The diameter of both capacitive loops becomes bigger and flattened, and such change can be attributed to the development of the protective layer on the surface [21] and also to the thickness
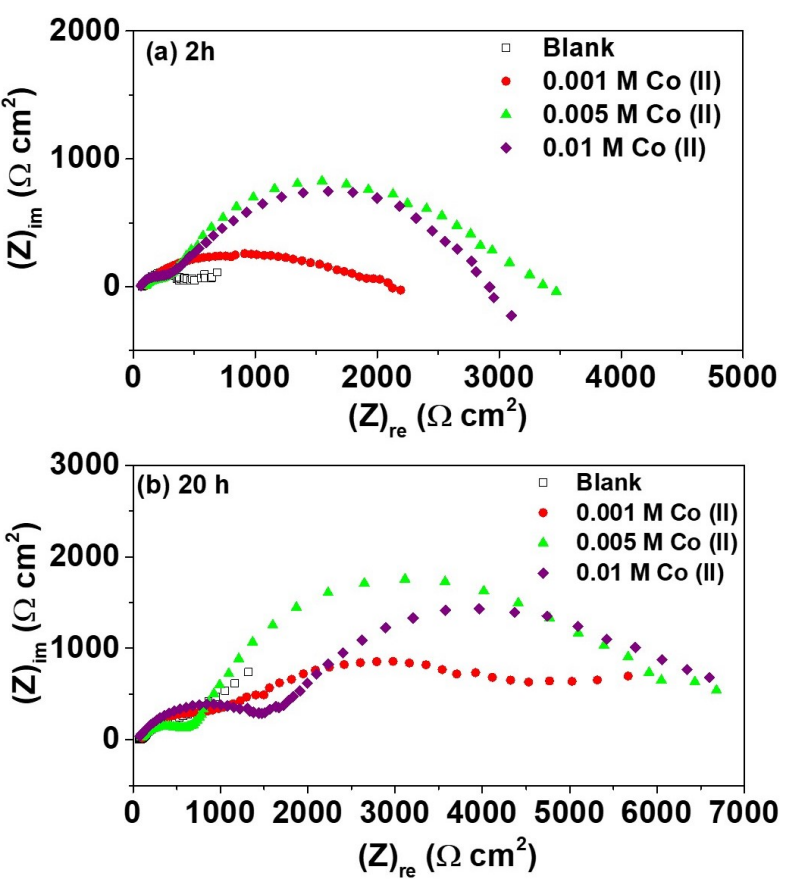

Figure 5: Nyquist plots obtained for the pre-cleaned HDG steel sheet immersed in $0.1 \mathrm{M} \mathrm{NaCl}$ containing different concentrations of Co(II) after (a) $2 \mathrm{~h}$ and (b) $20 \mathrm{~h}$.

of the double-layer. However, in the electrochemical plot obtained for $0.001 \mathrm{M}$, the third semi-circle appears at the low frequency relating to the on-going corrosion process occupied at the surface. This Co(II) concentration is not enough to protect the HDG steel surface for the long immersion time. In addition, to examine the protection, the experimental data were fitted by the equivalent circuits. Figure 6 presents the equivalent circuits corresponding to these Nyquist. The capacitances were replaced by the constant phase elements (CPE) for fitting which is defined as $Z_{\mathrm{CPE}}=$ $1 / Y(i \omega)^{\alpha}[19,22]$. These constitutes $R_{\text {sol }}$ as the resistance of the experimental solution; $R_{1}$ as the resistance of the passive layer formed by the corrosion products in parallel with a constant phase element $Q_{1} ; R_{2}$ and $Q_{2}$ correspond to the charge transfer resistance and the double layer capacitance, respectively. Following this electrical equivalent circuit, Table 2 represents the values of fitting parameters as a func-

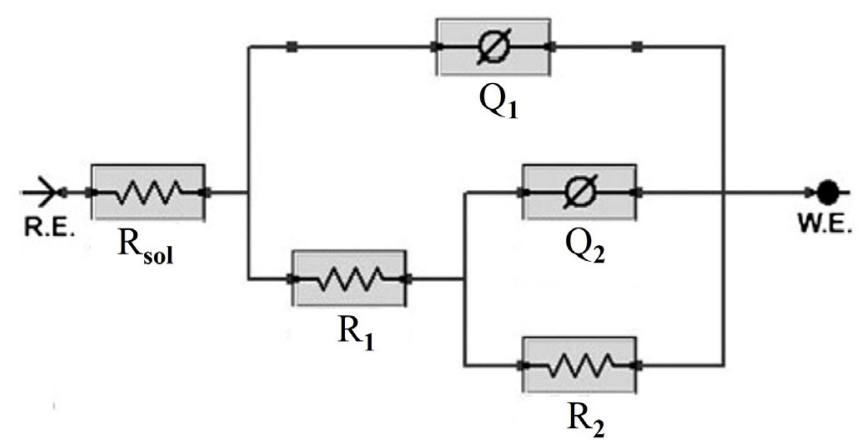

Figure 6: Electrical equivalent circuits correspond to the Nyquist plot with two capacitive loops. 
Table 2: Fitting parameters for two immersion times.

\begin{tabular}{|c|c|c|c|c|c|c|c|c|c|c|}
\hline & \multicolumn{2}{|c|}{$R_{1}\left(\Omega \mathrm{cm}^{2}\right)$} & \multicolumn{2}{|c|}{$Q_{1}\left(\mathrm{~F} \mathrm{~cm}^{-2} \mathrm{~s}^{-1}\right)$} & \multicolumn{2}{|c|}{$R_{2}\left(\Omega \mathrm{cm}^{2}\right)$} & \multicolumn{2}{|c|}{$Q_{2}\left(\mathrm{~F} \mathrm{~cm}^{-2} \mathrm{~s}^{-1}\right)$} & \multicolumn{2}{|c|}{$|Z|_{10 \mathrm{mHz}}\left(\Omega \mathrm{cm}^{2}\right)$} \\
\hline Concentration & $2 \mathrm{~h}$ & $20 \mathrm{~h}$ & $2 \mathrm{~h}$ & $20 \mathrm{~h}$ & $2 \mathrm{~h}$ & $20 \mathrm{~h}$ & $2 \mathrm{~h}$ & $20 \mathrm{~h}$ & $2 \mathrm{~h}$ & $20 \mathrm{~h}$ \\
\hline Blank & 424.2 & 629.1 & $791 \times 10^{-6}$ & $110 \times 10^{-6}$ & 536.1 & 689.5 & $1087 \times 10^{-6}$ & $11860 \times 10^{-6}$ & 696.4 & 1516.3 \\
\hline $0.001 \mathrm{M}$ & 480.1 & 322.2 & $496 \times 10^{-6}$ & $8.7 \times 10^{-6}$ & 111.5 & 1414 & $63.0 \times 10^{-6}$ & $1271 \times 10^{-6}$ & 2193.3 & 5711.1 \\
\hline $0.005 \mathrm{M}$ & 468.3 & 630.4 & $47.0 \times 10^{-6}$ & $9.6 \times 10^{-6}$ & 2756 & 5280 & $13.2 \times 10^{-6}$ & $14.7 \times 10^{-6}$ & 3168.2 & 6501.5 \\
\hline $0.001 \mathrm{M}$ & 487.6 & 1611 & $17.5 \times 10^{-6}$ & $8.1 \times 10^{-6}$ & 2657 & 5081 & $22.1 \times 10^{-6}$ & $29.2 \times 10^{-6}$ & 3109.1 & 6635.1 \\
\hline
\end{tabular}

tion of the immersion time. In addition, the impedance modulus $|Z|$ at the low frequency $\left(|Z|_{10 \mathrm{mHz}}\right)$ is also presented based on the following equation;

$$
|Z|=\sqrt{(Z)_{\mathrm{re}}^{2}+(Z)_{\mathrm{im}}^{2}},
$$

where $(Z)_{\text {re }}$ and $(Z)_{\text {im }}$ correspond to the impedance value of the real and imaginary parts in the Nyquist plot, respectively. The obtained values in Table 2 reveals that the development of the protective layers depends on the immersion time and also on the Co concentration. The value of $R_{1}$ increases with time of the measurements from 2 to $20 \mathrm{~h}$. This can be assumed to the passive layer formed by $\mathrm{Co}, \mathrm{Zn}$, and oxygen as explained in the literature $[1,8]$. The $Q_{1}$ deviation factors are in the range of $0.57 \leq n \leq 0.70$, meaning that the phenomenon is controlled by the diffusion. The protective layer in this case is reinforced due to absorption of the Co ions at the $\mathrm{Zn}$ surface during the immersion time (under stirring), that links to the increase of the $R_{2}$ resistance and the decrease of the $Q_{2}$ values. Due to the relation between the CPE value and the film thickness, the less the CPE value is, the more important the film thickness is [23], meaning the role of the Co-based double-layer capacitance. This double layer is developed significantly in the case of immersion in the solution containing 0.005 and $0.01 \mathrm{M}$ of the Co ions. Corresponding to the evolution of $R_{1}$ and $R_{2}$, the modulus values $|Z|_{10 \mathrm{mHz}}$ are also raised with the immersion time. In the pres-
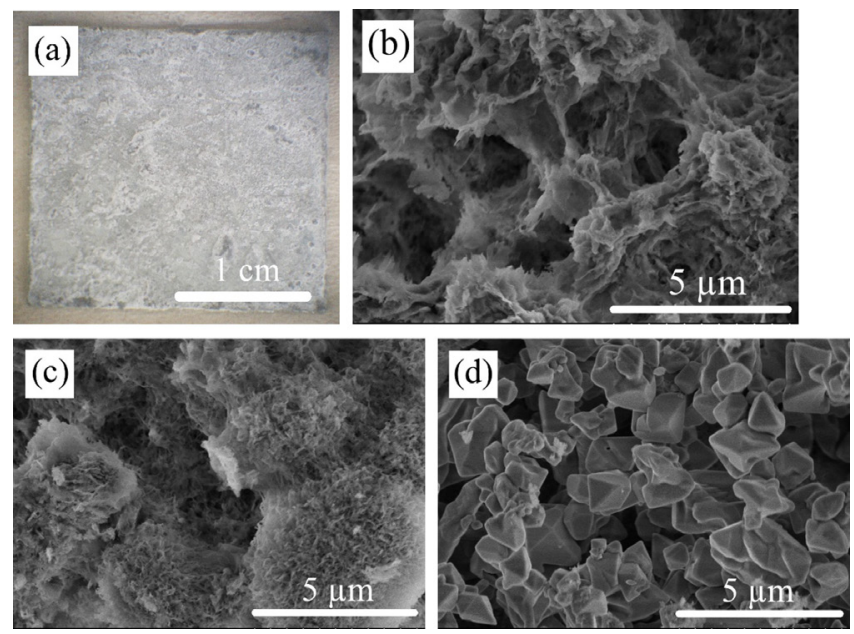

Figure 7: Optical image (a) and FE-SEM micrographs (b, c, d) of the HDG steel sample after $20 \mathrm{~h}$ immersed in the $0.1-\mathrm{M} \mathrm{NaCl}$ solution. ence of the higher Co content $(0.005$ and $0.01 \mathrm{M})$, the $|Z|_{10 \mathrm{mHz}}$ values are remarkable. This is reasonable with the Nyquist plot and reveals the activity of the Co ions in the protection of galvanized steel.

The details about this protection corrosion products are characterized and discussed in the next section.

\section{B. Morphological surface observations of gal- vanized steel after EIS measurements}

As characterized by the EIS measurements, the presence of the $\mathrm{Co}$ (II) ions, in particularly at the concentration of 0.01 $\mathrm{M}$, can help to reduce the corrosion phenomenon of the HDG steel substrate. After the EIS experiments $(20 \mathrm{~h}$ of immersion in the electrolyte solution), the steel substrates were gently cleaned by distilled water and examined for more detail with the help of FE-SEM micrograph and an optical observation. Figure 7 shows an optical image and the FE-SEM observations for the HDG steel substrate after $20 \mathrm{~h}$ immersed in the $0.1-\mathrm{M} \mathrm{NaCl}$ solution. The surface of HDG steel shows the white corrosion products that cover all exposed area [Figure 7(a)]. When analyzed these compounds by FE-SEM, lots of crystal structures can be observed as examples in Figure 7(b-d). These chemical products present the various types of crystals that are the result of reactions between zinc (in the surface) and the corrosive elements in the solution like oxygen and water according to the follow-

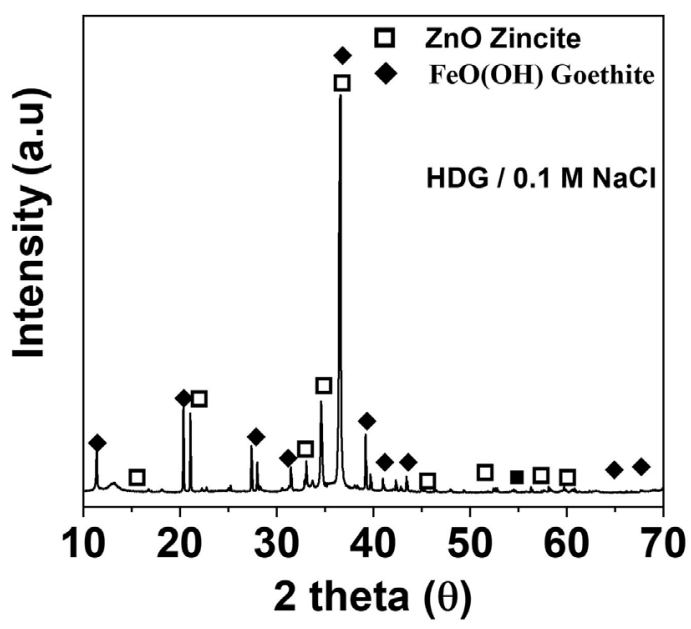

Figure 8: XRD pattern of the HDG steel sample after $20 \mathrm{~h}$ immersed in the $0.1-\mathrm{M}$ solution. 

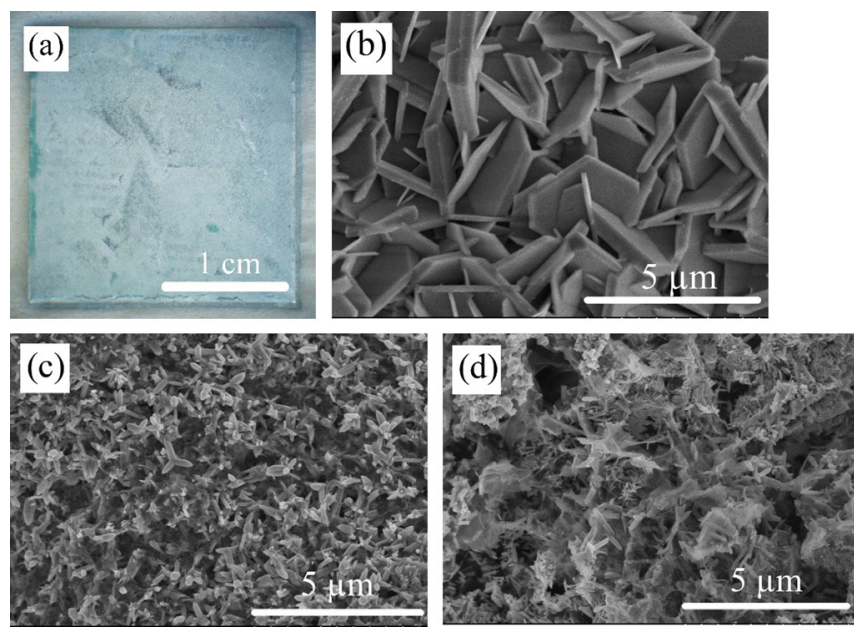

Figure 9: Optical image (a) and FE-SEM micrographs (b, c, d) of the HDG steel sample after $20 \mathrm{~h}$ immersed in the $0.1-\mathrm{M} \mathrm{NaCl}$ solution in the presence of $0.01 \mathrm{M}$ Co ions.

ing reactions [24]; dissolution of the zinc layer (the anodic reaction): $\mathrm{Zn} \rightarrow \mathrm{Zn}^{2+}+2 \mathrm{e}^{-}$, and the reduction of oxygen (the cathodic reaction): $\mathrm{O}_{2}+2 \mathrm{H}_{2} \mathrm{O}+4 \mathrm{e}^{-} \rightarrow 4 \mathrm{OH}^{-}$. The anodic reaction occurs in the zinc/oxide interface and the cathodic reaction occurs in the oxide/solution interface. Therefore, the oxide layer on the surface includes the zinc oxide layer available and zincite $(\mathrm{ZnO})$ formed by the following corrosion process; $\mathrm{Zn}^{2+}+2 \mathrm{OH}^{-} \rightarrow \mathrm{Zn}(\mathrm{OH})_{2} \rightarrow$ $\mathrm{ZnO}+\mathrm{H}_{2} \mathrm{O}$. In addition, it exists some $\mathrm{Fe}$ compounds as an impurity of the zinc coating, that are confirmed in the XRD patterns of Figures 8 and 10.

To highlight the reactivity of the Co(II) ions, Figure 9 shows surface appearance and FE-SEM images resulted after $20 \mathrm{~h}$ immersion of HDG steel in the $\mathrm{NaCl}$ solution containing $\mathrm{Co}^{2+}$. In comparison with Figure 7(a), the surface of HDG steel in Figure 9(a) has no damage. The FE-SEM observations also show various types of chemical compounds formed on the surface, but their crystalline morphology is different. In particular, a crystal structure like layered-double hydroxide is found in Figure 9(b), suggesting the formation of a protective $\mathrm{Zn}$-Co layer as a result of the inhibitive reaction of $\mathrm{Co}^{2+}$. This layered morphology is commonly observed when using a metallic salt as an inhibitor for the protection of alloys $[15,25,26]$. When analyzed the surface by XRD (Figure 10), an existence of zinc cobalt hydroxide $\mathrm{Zn}_{2} \mathrm{Co}_{3}(\mathrm{OH})_{10} \cdot 2 \mathrm{H}_{2} \mathrm{O}$ as a principal product was reported $(52.5 \%)$. It is also existed cobalt zinc oxide $\left(\mathrm{Zn}_{0.97} \mathrm{Co}_{0.03}\right) \mathrm{O}$ in the XRD pattern. These compounds can be explained by the development of $\mathrm{Co}$ at the $\mathrm{Zn}$ surface as a part of cathodic reaction $\mathrm{Co}^{2+}+2 \mathrm{e}^{-} \rightarrow$ Co [3]. With an enough Co concentration, uncharged cobalt is probably incorporated into the zinc oxide framework, leading to the development of the protective zinc cobalt oxide/hydroxide layer. These results confirm the inhibitive ability of $\mathrm{Co}(\mathrm{II})$ in the corrosion protection of galvanized steel.

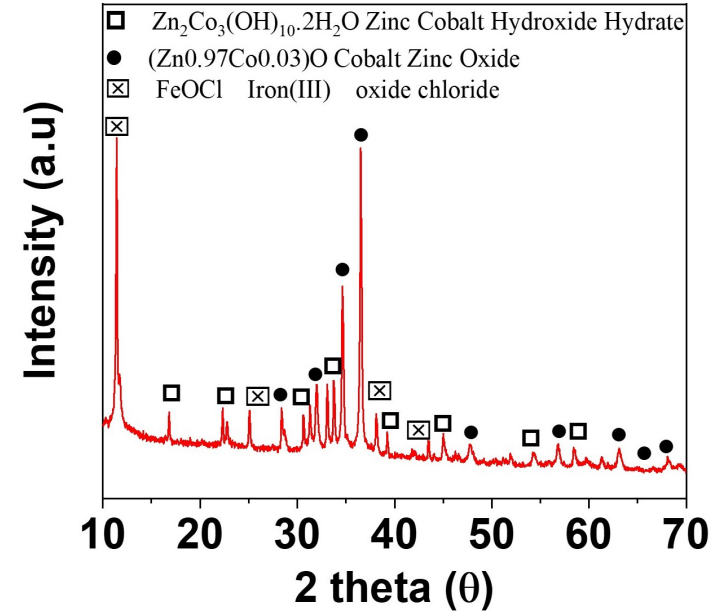

Figure 10: XRD patterns of the HDG steel sample after $20 \mathrm{~h}$ immersed in the $0.1-\mathrm{M} \mathrm{NaCl}$ solution in the presence of $0.01 \mathrm{M} \mathrm{Co}$ ions.

\section{CONCLUSION}

This study focuses on the inhibitive properties of cobalt(II) ions on the corrosion protection of galvanized steel in the electrolyte solution. The results revealed the inhibitive ability of $\mathrm{Co}$ (II) from cobalt(II) nitrate by the formation of a protective layer on the metallic substrate that retards the attack of corrosive species in the measured environment:

- The evolution of the OCP parameter and the polarization measurement reveal that the inhibitive property of Co(II) happens at the anodic branch. The inhibitive efficiency reaches a high value (96\%) in the case of using $0.01 \mathrm{M}$ of $\mathrm{Co}(\mathrm{II})$ and is prolonged during the long immersion time.

- The EIS measurement had also proved the protective effect of $\mathrm{Co}$ (II) that related to the formation of a passive layer on the surface. The thickness of this layer is also reinforced during immersion as a result of absorption of the Co cation to the $\mathrm{Zn}$ layer.

- Existence and characterization of this passive layer have proved by the FE-SEM micrographs and the XRD analysis. The results confirm that Co(II) inhibits the corrosion of galvanized steel by an anodic mechanism, due to the formation of zinc cobalt hydroxide $\mathrm{Zn}_{2} \mathrm{Co}_{3}(\mathrm{OH})_{10} \cdot 2 \mathrm{H}_{2} \mathrm{O}$ and cobalt zinc oxide on the $\mathrm{Zn}$ surface. The combination of $\mathrm{Zn}$ dissolution $\left(\mathrm{Zn} \rightarrow \mathrm{Zn}^{2+}+2 \mathrm{e}^{-}\right)$, the presence of water and oxygen, and absorption of the Co ions on the $\mathrm{Zn}$ surface result in the formation of the $\mathrm{Zn}$-Co structure. The XRD analysis shows that the principal components of this protective film are zinc cobalt hydroxide and cobalt zinc oxide, that form a crystalline structure like layered-double hydroxide. These results prove the role of the cobalt cation as a corrosion inhibitor for galvanizes steel and suggest the use of metallic cations as inhibitors for the protection of the metallic substrate. 


\section{Acknowledgments}

The authors would like to thank ITT-VAST for financial support.

\section{References}

[1] M. Mouanga, P. Bercot, and J. Y. Rauch, Corros. Sci. 52, 3984 (2010).

[2] R. Zandi Zand, K. Verbeken, V. Flexer, and A. Adriaens, Mater. Chem. Phys. 145, 450 (2014).

[3] H. Leidheiser, Jr. and I. Suzuki, J. Electrochem. Soc. 128, 242 (1981).

[4] N. S. Azmat, K. D. Ralston, B. C. Muddle, and I. S. Cole, Corros. Sci. 53, 1604 (2011).

[5] C. N. Panagopoulos, E. P. Georgiou, and C. Markopoulos, Corros. Sci. 70, 62 (2013).

[6] T. Prosek, D. Thierry, C. Taxén, and J. Maixner, Corros. Sci. 49, 2676 (2007).

[7] K. Aramaki, Corros. Sci. 43, 1985 (2001).

[8] I. A. Kartsonakis, S. G. Stanciu, A. A. Matei, R. Hristu, A. Karantonis, and C. A. Charitidis, Corros. Sci. 112, 289 (2016).

[9] K. Aramaki, Corros. Sci. 43, 2201 (2001).

[10] K. Aramaki, Corros. Sci. 44, 871 (2002).

[11] M. G. S. Ferreira, R. G. Duarte, M. F. Montemor, and A. M. P. Simões, Electrochim. Acta 49, 2927 (2004).

[12] M. Golabadi, M. Aliofkhazraei, M. Toorani, and A. Sabour Rouhaghdam, J. Ind. Eng. Chem. 47, 154 (2017).

[13] M. Mahdavian and M. M. Attar, Corros. Sci. 51, 409 (2009).

[14] A. W. Phelps, J. A. Sturgill, J. T. Swartzbaugh, US Patent $7291217,2007$.

[15] T. T. Thai, A. T. Trinh, G. V. Pham, T. T. T. Pham, and H. Nguyen Xuan, Corros. Sci. Technol. 19, 8 (2020).

[16] A. C. Balaskas, M. Curioni, and G. E. Thompson, J. Electrochem. Soc. 161, C389 (2014).
[17] K. H. Kim, S. H. Lee, N. D. Nam, and J. G. Kim, Corros. Sci. 53, 3576 (2011).

[18] M. Meeusen, L. Zardet, A. M. Homborg, M. Lekka, F. Andreatta, L. Fedrizzi, B. Boelen, J. M. C. Mol, and H. Terryn, Corros. Sci, 173, 108780 (2020).

[19] E. A. Matter, S. Kozhukharov, M. Machkova, and V. Kozhukharov, Corros. Sci. 62, 22 (2012).

[20] H. Tamura, N. Katayama, and R. Furuichi, J. Colloid Interface Sci. 195, 192 (1997).

[21] S. Feliu, Jr., Metals 10, 775 (2020).

[22] T. T. Thai, A. T. Trinh, and M.-G. Olivier, Prog. Org. Coat. 138, 105428 (2020).

[23] T. T. Thai, M.-E. Druart, Y. Paint, A. T. Trinh, and M.-G. Olivier, Prog. Org. Coat. 121, 53 (2018).

[24] Y. Meng, L. Liu, D. Zhang, C. Dong, Y. Yan, A. A. Volinsky, and L.-N. Wang, Bioact. Mater. 4, 87 (2019).

[25] T. T. Thai, A. T. Trinh, T. T. T. Pham, X. H. Nguyen, G. V. Pham, and T. X. H. To, e-J. Surf. Sci. Nanotechnol. 18, 239 (2020). [26] P. Visser, H. Terryn, and J. M. C. Mol, Surf. Interface Anal. 51, 1276 (2019).

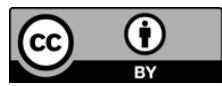

All articles published on e-J. Surf. Sci. Nanotechnol. are licensed under the Creative Commons Attribution 4.0 International (CC BY 4.0). You are free to copy and redistribute articles in any medium or format and also free to remix, transform, and build upon articles for any purpose (including a commercial use) as long as you give appropriate credit to the original source and provide a link to the Creative Commons (CC) license. If you modify the material, you must indicate changes in a proper way.

Published by The Japan Society of Vacuum and Surface Science 